Cahiers de recherches médiévales siècle)

\title{
Entre réforme du royaume et enjeux dynastiques
}

Le magistère intellectuel et moral de l'université de Paris au sein de la Ligue (1576-1594)

\section{Thierry Amalou}

\section{(2) OpenEdition \\ Journals}

Édition électronique

URL : https://journals.openedition.org/crm/11692

DOI : $10.4000 / \mathrm{crm} .11692$

ISSN : $1955-2424$

Éditeur

Honoré Champion

Édition imprimée

Date de publication : 20 novembre 2009

Pagination : 145-166

ISSN : $1272-9752$

Référence électronique

Thierry Amalou, «Entre réforme du royaume et enjeux dynastiques », Cahiers de recherches médiévales [En ligne], 18 | 2009, mis en ligne le 15 décembre 2012, consulté le 15 décembre 2022. URL : http:// journals.openedition.org/crm/11692; DOI : https://doi.org/10.4000/crm.11692 


\title{
RM
}

\section{Entre réforme du royaume et enjeux dynastiques Le magistère intellectuel et moral de l'université de Paris au sein de la Ligue (1576-1594)}

\begin{abstract}
On the $7^{\text {th }}$ of January 1589, the Faculty of Theology of Paris became guarantor of the 'constitutionality' of the Catholic League, releasing the king's subjects from their allegiance. The Faculty considered Henry III's implication in the assassinations of members of the Guise family a breach of the 'contract' contained in the Edict of Union which it had actively promoted. Nevertheless, when in 1591 the radical fringe group of les Seize was eliminated, this contributed to the reduction of the influence of the League's theologians, who had little influence on the outcome of the Estates-General of 1593. But their ultimate failure was largely due to the isolation of the Monarchomach and theocratic positions, which, contrary to the official resolutions of the Sorbonne, opposed the Salic Law. This denial of one of the fundamental laws of the kingdom constituted an attack on a powerful founding myth of the University of Paris, the translatio studii, and brought discredit upon the entire University.

Résumé: Le 7 janvier 1589, la faculté de théologie de Paris devient la garante du " constitutionnalisme" de la Ligue en déliant les sujets de leur obéissance au roi. La responsabilité d'Henri III dans l'assassinat des Guises constituait, selon elle, une rupture du " contrat » contenu dans l'édit d'Union dont elle avait assuré la promotion. L'élimination, en 1591, d'une partie de la frange radicale des Seize contribue néanmoins à réduire l'influence des théologiens ligueurs: ces derniers pèsent peu dans l'issue des états généraux de 1593. Mais leur échec final doit beaucoup à l'isolement des thèses monarchomaques qui remettent en cause la loi salique, contrairement aux résolutions officielles de la Sorbonne. En niant l'une des lois fondamentales du royaume, ces positions contredisent en effet un puissant mythe fondateur de l'université de Paris, la translatio studii, jetant ainsi le discrédit sur leurs auteurs et leur institution d'origine.
\end{abstract}

Rarement l'insertion sociale et politique du corps universitaire dans la vie de la capitale fut aussi intense qu'au moment de la Ligue. Certes les interventions de l'Université dans les débats politiques, tout particulièrement celles de la faculté de théologie, qui nous retiendront ici, ne sont pas une nouveauté. Depuis le règne de Charles VI, des théologiens comme Gerson ont su relayer les aspirations des légistes et de la société civile à réformer le royaume'. Les docteurs de Sorbonne et leur institution ne se contentaient pas seulement d'enseigner et de conférer des grades ; ils contribuaient à fixer l'orthodoxie en matière de dogme. Les articles de foi qu'ils rédigèrent en 1543, qui avaient d'abord pour vocation de lutter contre le protestantisme en facilitant une censure de la prédication, finirent par revêtir le

${ }^{1}$ E. Marmursztejn, L'autorité des maîtres. Scolastique, normes et société au XIII siècle, Paris, Les Belles Lettres, 2006, p. 12-13 et S. Lusignan, La construction d'une identité universitaire en France, $X I I I^{e}-X V^{e}$ siècles, Paris, Publications de la Sorbonne, 1999, p. 221 228.

Cahiers de Recherches Médiévales, 18, 2009 
caractère de loi du royaume, une fois approuvés par François $\mathrm{I}^{\mathrm{er}}$ et enregistrés par le parlement de Paris². Néanmoins la résolution du 7 janvier 1589 dans laquelle la Sorbonne - entendons, par là, la faculté de théologie, selon une métonymie usuelle ${ }^{3}$ délie les sujets de leur obéissance envers Henri III, constitue une décision inouïe dont la portée est envisagée par l'historiographie, jusqu'à aujourd'hui, comme un acte de déchéance pour le roi, une légitimation de la rébellion de la Sainte-Union qui devait conduire au régicide 4 .

La Ligue en tant qu'organisation partisane aux composantes multiples (nobiliaire avec les Guises, bourgeoise avec les Seize, cléricale avec les théologiens de la Sorbonne) fut la réponse des catholiques zélés à la crise de succession dynastique des derniers Valois. La disparition de François d'Anjou, en 1584, et l'absence de descendant pour Henri III nourrissaient chez ces derniers l'angoisse de voir accéder au trône de France, selon les dispositions de la loi salique, Henri de Bourbon, roi de Navarre, c'est-à-dire un «hérétique et relaps». Mais comment l'autorité doctrinale et morale de la Sorbonne a-t-elle pu s'opposer à ce point à l'obéissance au souverain légitime, alors que la filiation au roi de France depuis Charlemagne (translatio studii) était encore au $\mathrm{XVI}^{\mathrm{e}}$ siècle l'un des mythes constitutifs de l'identité de l'université de Paris ${ }^{5}$ ? En observant l'immixtion de la faculté de théologie dans la politique ${ }^{6}$, il nous semble possible de distinguer trois

${ }^{2}$ J. K. Farge, Orthodoxy and Reform in early Reformation France. The Faculty of Theologie of Paris, 1500-1543, Leiden, Brill, 1985, p. 208-211. Les articles de foi de 1543 servent de modèle à la confession de foi que le parlement de Paris impose à ses officiers au début des guerres de Religion, voir S. Daubresse, Le parlement de Paris ou la voix de la raison, Genève, Droz, 2005, p. 109.

${ }^{3}$ M.-M. Compère, Les collèges français $16^{e}-18^{e}$ siècles, t. 3, Paris, INRP, p. 328-329.

${ }^{4}$ C. Labitte, De la démocratie chez les prédicateurs de la Ligue, Paris, 1841, Imprimerie H. Fournier, rééd. 1866, p. 125 ; E. Barnavi, Le parti de Dieu. Étude sociale et politique des chefs de la Ligue parisienne, Bruxelles, Nauwelaerts, p. 129 ; Nicolas Le Roux, Un régicide au nom de Dieu, Paris, Gallimard, 2006, p. 162.

${ }^{5}$ Certes, un grand gallican comme Étienne Pasquier ne croit plus en cette filiation mais «honore infiniement la mémoire» de Jean Gerson et l'idée d'une fondation royale remontant à Philippe Auguste, voir Étienne Pasquier, Les recherches en la France, t. III, éd. M.-M. Fragonard et F. Roudaut, Paris, Champion, 1996, p. 1746-1748. Mais en 1586 l'avocat au Parlement Louis Servin continue à soutenir que l'université de Paris doit son origine à Charlemagne, voir le Plaidoyer de Maistre Louis Servin advocat en parlement pour maistre Jean Hamilton écossois, licencié en la faculté de théologie, présenté par l'Université de Paris, pourvu de la cure Saint Cosme et s. Damien appelant et demandeur en complaincte..., chez Adrien Perier, Paris, 1586, p. 9.

${ }^{6}$ Les sources mobilisées ici sont moins les traités politiques et les sermons qui relèvent des productions doctrinales ou pastorales individuelles que les arbitrages collectifs demandés par les pouvoirs civils à la faculté de théologie. En tout, six «avis et résolutions », édités, souvent traduits en français et largement diffusés entre le 7 janvier 1589 et le 7 mai 1590. Voir D. Pallier, Recherches sur l'imprimerie à Paris pendant la Ligue : 1585-1594, Genève, Droz, 1975. Les registres manuscrits des conclusions, contrairement à ceux de la première moitié du $\mathrm{XVI}^{\mathrm{e}}$ siècle, n'ont pas été conservés, mais les transcriptions ultérieures de César 
phases qui éclairent en partie ce paradoxe : celle de la confiance des milieux gallicans (1576-1588) ; celle de la légitimation du projet politique ligueur (1588$1591)$; celle des divisions et de la perte d'influence (1591-1594).

Un corps qui inspire la confiance grandissante des milieux gallicans (15761588)

Il faut bien partir de ce constat préalable. L'époque de Montaigne n'est pas celle de Rabelais, et les critiques humanistes contre les "sorbonagres » et les « théologastres » semblent avoir perdu de leur force. Le 10 octobre 1585, Henri de Navarre lui-même, excommunié un mois plus tôt par Pie V, rend un hommage appuyé aux membres de la faculté de théologie pour avoir toujours su garder « les privilèges et droits de l'Église gallicane $»^{7}$. Il les exhorte à réunir un concile libre et général pour établir " une ferme paix en ce royaume ", reprenant ainsi à son compte un lieu commun gallican qui connaît une vigueur nouvelle depuis les états généraux de Blois de $1576^{8}$. C'est que la faculté de théologie, dans la droite ligne du «parti conservateur » de l'orthodoxie catholique décrit par J. K. Farge, demeure un bastion du gallicanisme qui, associé au parlement, cherche à protéger le fonctionnement corporatif d'un système éducatif hérité.

\section{De l'antiramisme à la lutte contre les Jésuites}

Si les réformes pédagogiques de Pierre de la Ramée lui valurent un succès retentissant dans l'Europe protestante, il n'en est pas de même en France. Ses critiques d'Aristote et son désir d'allier la rhétorique à l'art de raisonner revenaient à privilégier le cycle des arts sur l'enseignement de la théologie et de la scolastique'. Une large réprobation, accentuée par l'adhésion de Ramus au calvinisme, parcourut non seulement la Sorbonne mais l'ensemble de l'Université et des Lecteurs royaux ${ }^{10}$.

Égasse Du Boulay, greffier de l'Université, nous en donnent néanmoins un aperçu : Historia Universitatis Parisiensis, vol. 6, Paris, chez Noël et P. de Bresche, 1673.

${ }^{7}$ Deux lettres du roy de Navarre à messieurs les gens tenans la cour de Parlement à Paris et à messieurs de la faculté de théologie du collège de Sorbonne, s. 1., 1586, p. 12-13

${ }^{8}$ A. Tallon, «La fin d'un instrument de paix : le concile général », Paix des armes, paix des âmes, dir. P. Mironneau et I. Pébay-Clottes, Paris, Imprimerie nationale, 2000, p. 24, rappelle qu'à partir de 1577, Henri de Navarre et ses publicistes font très habilement savoir leur désir d'accepter les décisions d'un concile libre qu'il soit général ou national. Cette prise de position suscita l'intérêt des milieux gallicans mais la faculté de théologie, contrairement au parlement, refusa de recevoir les lettres du 10 octobre, voir à ce sujet S. Daubresse, op. cit., p. 233.

${ }^{9}$ Voir F. Laplanche, «Le mouvement intellectuel et les Églises », Histoire du christianisme des origines à nos jours., dir. J.-M. Mayeur et alii, t. 8, Le temps des confessions (1530-1620), Paris, Fayard Desclée, 1992, p. 1068-1069 ; G. Oldrini, «Éduquer au savoir. La formation ramiste entre université et société », Ramus et l'Université, Paris, Presses de l'École normale supérieure, 2004, p. 176-187.

${ }^{10}$ Sur l'opposition des Lecteurs royaux à Ramus, voir notamment le cas du lecteur en langue hébraïque Gilbert Génébrard qui fut député de l'université de Paris aux états de Blois de 
Les milieux gallicans hostiles aux protestants partageaient l'antiramisme universitaire. On en trouve la traduction dans les arrêts de réformation de l'université de Paris, publiés par le Parlement les 13 août et 20 septembre 1575, et amplifiés le 22 septembre 1577, qui entendent repousser "l'invasion" de la dialectique (c'est-à-dire ici de la rhétorique) aussi bien dans les classes de grammaire qu'à la faculté des $\operatorname{arts}^{11}$. L'Université entérine ces décisions sans résistance : ainsi le 22 avril 1577, l'assemblée de ses députés réunis au couvent des Mathurins enjoint aux principaux des collèges de veiller à ce que l'enseignement de la rhétorique ne s'étende pas aux préceptes de la philosophie et de la dialectique ${ }^{12}$.

Tout autant que la défense d'Aristote qui visait à préserver les fondements corporatifs du système universitaire, la lutte bien connue contre les Jésuites que l'Université refusait d'intégrer en son sein bénéficia du soutien du parlement. Ce fut l'occasion en 1565 d'un procès rendu fameux par le réquisitoire de l'avocat Étienne Pasquier dénonçant leur vœu d'obéissance au pape, la pauvreté de leur enseignement lié à leur apostolat itinérant et leur statut particulier (mi-séculier, mi-régulier) source de désordre pour la hiérarchie du corps universitaire ${ }^{13}$. Le trouble suscité par les Jésuites, pour reprendre la formule de M.-M. Fragonard, tenait d'abord à leur succès et à la concurrence qu'ils représentaient pour la faculté des arts. De la même façon, leurs leçons publiques de théologie, notamment celles du père Maldonat, qui suscitèrent l'engouement dès 1564 , remettaient en cause le monopole éducatif et le magistère de la faculté de théologie ${ }^{14}$. De surcroît, les thèses soutenues par Maldonat cherchaient à promouvoir l'autorité du concile de Trente sans tenir compte des traditions locales. Ainsi, lorsqu'il refusa publiquement d'admettre, c'est-à-dire d'enseigner, le caractère dogmatique de l'Immaculée Conception dont la Sorbonne faisait officiellement la promotion depuis $1498^{15}$, il suscita la fureur puis la censure de cette dernière ${ }^{16}$. Ni le soutien apporté aux disciples d'Ignace de Loyola par l'évêque de Paris, Pierre de Gondi, ni la protection que leur offrit Henri III, ne permirent leur intégration à l'Universitél ${ }^{17}$. C'est en vain que le cardinal de Bourbon

1576 : K. Meerhoff et J.-C. Moissan, Autour de Ramus. Le combat, Paris, Champion, 2005, p. 10 .

${ }^{11}$ Arrestz de la cour de Parlement donnez par provision les XIII d'aoust 1575 et XX de septembre 1577 pour le règlement et réformation de l'Université de Paris, Paris, Frederic Morel, 1577, p. 24 : interdiction tant aux artiens qu'aux grammairiens « de lire ne interpréter autres livres que ceux qui concernent et appartiennent à leurs professions. Sçavoir est les grammairiens livres de grammaires, rhétorique et poésie - et non de dialectique - et aux artiens livres de philosophie $»$.

${ }^{12}$ César Égasse Du Boulay, op. cit., t. 6, p. 751.

${ }^{13}$ A. Douarche, L'Université de Paris et les Jésuites (XVI et XVI siècles), Paris, Hachette, 1888, p. 81-83.

${ }^{14}$ M.-M. Compère, op. cit., p. 362.

${ }^{15}$ J. K. Farge, op. cit., p. 163.

${ }^{16}$ J.-M. Prat, Maldonat et l'université de Paris au XVI ${ }^{e}$ siècle, Paris, Julien, Lanier et cie, 1856, p 349-368. V. Martin, Le gallicanisme et la réforme catholique. Essai historique sur l'introduction en France des décrets du concile de Trente (1563-1615), Paris, 1919, rééd. Genève, Slatkine-Megariotis, 1975, p. 119.

${ }^{17}$ A. L. Martin, Henry III and the jesuit politicians, Genève, Droz, 1973, p. 177-178. 
tenta une ultime conciliation en $1578-1579^{18}$. Un article apparemment anodin de l'arrêt du parlement pour la réformation de l'Université comportait une brève remarque sur la décence des tenues vestimentaires des élèves du collège de Clermont. C'était cependant laisser entendre que celui-là n'était pas fondamentalement différent des autres collèges parisiens. L'Université y vit aussitôt une menace et s'empressa d'abolir l'article en question ${ }^{19}$. Le front commun des gallicans du Parlement et de l'Université s'étendait cependant à un vaste champ d'action que la politique fiscale de la monarchie, en empiétant sur les privilèges et les libertés, avait contribué à former contre elle.

\section{La défense commune des "libertés gallicanes »}

D'autant que l'hostilité du Parlement à la réception du concile de Trentemalgré les tensions qui s'accentuaient entre les gallicans et les papes Grégoire XIII, puis Sixte Quint ${ }^{20}$ - ne lui valut pas de s'opposer frontalement à la faculté de théologie. Certes, la Sorbonne restait solidaire du clergé qui, notamment lors de l'assemblée de Melun en 1579, s'était prononcé en faveur de la réception du concile de Trente ${ }^{21}$. Mais elle s'engagea surtout sur un autre terrain revendicatif qui avait le soutien du Parlement : en janvier 1580, elle tenta d'obtenir d'Henri III le retrait du concordat de Bologne et le retour à la Pragmatique Sanction de Bourges ${ }^{22}$. C'était là retrouver une cause commune défendue avec ardeur depuis le règne de François $\mathrm{I}^{\mathrm{er}_{23}}$. Les convergences gallicanes s'exprimèrent aussi dans la défense du droit de patronage de l'Université à l'occasion du procès de Jean Hamilton. Ce dernier, d'origine écossaise, recteur de l'Université en 1584, puis licencié et docteur en théologie en 1586, fut nommé par la nation allemande à la cure parisienne de SaintCôme et Saint-Damien ${ }^{24}$. Pierre Tenrier, qui avait obtenu la résignation du précédent curé, contesta l'attribution du bénéfice. Son avocat, le célèbre juriste érudit Antoine Loisel, prétendit alors que l'Université était un corps ecclésiastique, indépendant du pouvoir royal et dont les " plus beaux privilèges » avaient été concédés par le SaintSiège $^{25}$. Toutefois le Parlement donna raison à l'Université estimant qu'elle

\footnotetext{
${ }^{18}$ César Égasse Du Boulay, op. cit., t. 6, p. 763-765.

${ }^{19}$ Ibid., p. 747 (21 janvier 1576).

${ }^{20}$ S. Daubresse, op. cit., p. 228-233.

${ }^{21}$ L. Serbat, Les assemblées du clergé de France. Origines, organisation, développement, 1561-1615, Paris, H. Champion, 1906, p. 295-296.

${ }^{22} 29$ janvier 1580 : l'Université agit avec l'aide du premier président du Parlement, d'après $\mathrm{P}$. Ferret, La faculté de théologie de Paris et ses docteurs les plus célèbres, époque moderne, t. I, Paris, Picard, 1900, p. 317.

${ }^{23}$ J.-K. Farge, op. cit., p. 253.

${ }^{24}$ V. Angelo, Les curés de Paris..., p. 733.

${ }^{25}$ Antoine Loisel, De l'université de Paris et qu'elle est plus ecclésiastique que séculière, Paris, chez Abel l'Angelier, 1587, p. $22^{\mathrm{v}}$ : «En somme, ils tiennent quasi tout ce qu'ilz ont de plus beau des papes de Rome lesquelz pour cette cause il recognoissent par tous leurs escritz comme leurs supérieurs ».
} 
échappait au concordat en raison de son statut particulier et de ses privilèges anciens donnés par Charlemagne ${ }^{26}$.

L'Université s'opposa avec vigueur, mais sans succès, à la création des messagers royaux en 1576, qui mettait fin à son monopole sur les postes. Les récriminations adressées alors à Henri III ne sont guère éloignées de celles du Parlement demandant la suppression des offices nouveaux ${ }^{27}$. Avec la détérioration économique des années 1580 , les plaintes à l'égard de la politique royale et de ses expédients financiers devaient prendre de l'ampleur ${ }^{28}$. C'est dans ce contexte que le docteur en théologie Jean Boucher, l'un des pères fondateurs de la Ligue parisienne en $1585^{29}$, lié par sa famille au milieu du Parlement, exerce son rectorat en s'illustrant précisément dans la défense des privilèges qu'il estimait en péril. Obtenant un succès éclatant dans l'affaire du droit de parchemin, succès dont il fit lui-même la publicité, Boucher partait à la conquête de l'opinion parisienne ${ }^{30}$. Nous savons en effet, depuis les travaux de Robert Descimon, que l'un des thèmes qui mobilisèrent la bourgeoisie de la capitale dans les rangs de la Ligue fut la défense d'un système corporatif hérité du Moyen Âge, la bonne ville et ses libertés, système que les ligueurs estimaient menacé par les transformations sociales liées au développement de l'État monarchique ${ }^{31}$. On voit donc ici, nous semble-t-il, se dessiner la genèse des affinités électives entre la composante bourgeoise de la Ligue et une figure charismatique de l'Universités ${ }^{2}$. Le combat contre l'hérésie, vocation traditionnelle de la faculté de théologie, ne pouvait que renforcer ce rapprochement au nom du zèle catholique.

\section{La discipline des mours pour lutter contre l'hérésie}

Plusieurs indices attestent de l'engagement des théologiens à accorder davantage la discipline des études à la défense du dogme catholique. Ce désir de discipline, au sens le plus large du terme, traverse toute la société au seuil des

\footnotetext{
${ }^{26}$ Plaidoyer de Maistre Louis Servin advocat en parlement pour maistre Jean Hamilton écossois, licencié en la faculté de théologie, présenté par l'Université de Paris, pourvu de la cure Saint Cosme et s. Damien appelant et demandeur en complaincte..., Paris, chez Adrien Perier, 1586.

${ }^{27}$ César Égasse Du Boulay, Historia Universitatis Parisiensis..., t. 6, p. 769.

${ }^{28}$ S. Daubresse, op. cit., chap. VI : La montée des mécontentements (1584-1587), p. 355-414.

${ }^{29}$ E. Barnavi, op. cit., p. 21.

${ }^{30}$ Johannis Buchaeri Parisini, academiae rectoris, ac socii sobonici oratio, pro jure pergameni, habita senatu XVI martii 1581, Paris, chez Denis Du Pré, 1581. Un jugement du Parlement en sa faveur permit à Boucher de faire saisir les bottes de parchemin que Nicolas Le Vasseur, marchand drapier peu soucieux des privilèges de l'Université, n'avait pas présentées dans la halle aux parchemins (située dans le couvent des Mathurins) où elles auraient dû recevoir la marque du recteur.

${ }^{31}$ Voir R. Descimon, Qui étaient les Seize ? Mythes et réalités de la Ligue parisienne : 1585 1594, Paris, Fédération des sociétés historiques et archéologiques de Paris et de l'Île-deFrance, Klincksieck, 1983, p. 88-90 et 297-298 ; Id., «La ligue à Paris (1585-1594) : une révision », Annales ESC, 1982, vol. 37, n 1, p. 88-91.

${ }^{32}$ Pour une biographie de Jean Boucher, voir Abbé P. Feret, La faculté de théologie et ses docteurs les plus célèbres, époque moderne, t. IV, Paris, Picard, 1906, p. 209-225.
} 
années 1580. Des laïcs aux clercs, des élites au peuple, nombreux sont ceux qui expriment la conscience aiguë de la corruption et le désir de s'amender. Les gestes de pénitence collective perceptibles dans les dévotions extérieures expriment aussi l'espoir d'apaiser la colère divine en réduisant définitivement l'hérésie ${ }^{33}$. La réception des décrets tridentins par la réunion de plusieurs conciles provinciaux pousse alors à refaçonner la vie publique et privée pour la mettre davantage en conformité avec le dogme : c'est l'une des manifestations parmi les plus visibles du processus de confessionalisation ${ }^{34}$.

Les critiques fustigeant la dépravation de mœurs soumises aux mondanités, ne sont pas qu'un lieu commun visant la vie de la cour d'Henri III $^{35}$. Les projets de réforme de l'Université de 1575 et 1577 insistent sur la nécessité d'une réglementation somptuaire: le port de manteaux ou de reîtres sans manches est interdit tant aux régents qu'aux écoliers. Le port d'armes est également prohibé ${ }^{36}$. À la «somptuosité des habits» est préférée la décence des bonnets ronds, des manteaux à manches ou des chaperons à bourrelets conformes au statut social l'estat - des régents ${ }^{37}$. Certes ce trait peut sembler banal, tant il est fréquent dans les réglementations sur l'usage des vêtements, réitérées lors des réformes antérieures de l'Université. Toutefois ces dernières étaient d'abord soucieuses de ce que l'usage quotidien du vêtement à l'université soit le reflet de la hiérarchie sociale et elles n'exprimaient pas d'hostilité envers les fourrures, soies et gants des docteurs ${ }^{38}$. En revanche, le souci de réglementer les tenues vestimentaires n'est peut-être pas étranger au désir de cléricaliser le monde universitaire. Ainsi, contrairement au XV siècle où les régents en médecine étaient autorisés à se marier, l'Université espère imposer le célibat ${ }^{39}$. Ce statut clérical pousse la faculté de théologie à rappeler à ses

\footnotetext{
${ }_{33}$ M. Greengrass, Governing Passions. Peace and Reform in the French Kingdom, 15761585, Oxford, Oxford University Press, 2007, p. 303-311.

${ }^{34}$ G. Chaix, "La confessionnalisation. Note critique", Bulletin de la Société de l'histoire du protestantisme français, octobre-décembre 2002, p.851-865; Ph. Benedict, "Confessionalization in France? Critical reflexions and new evidence », The Faith and Fortunes of France's huguenots, New York, 2001, p. 307-325.

${ }^{35}$ Ce n'est pas pour rien si l'imprimeur Benoist Chauchel met en avant l'approbation des docteurs de Sorbonne pour éditer le Discours miraculeux, inouy et épouvantable avenu à Anvers...d'une jeune fille flamende qui par la vanité et trop grande curiosité de ses habits et collez à fraise goderonnez à la nouvelle mode fut étranglée du diable et son corps après telle punition divine estant au cercueil transformé en un chat noir en présence de tout le peuple assemblée, Paris, 1582, qui se termine par un sonnet aux dames françaises destiné à leur faire rejeter « la somptuosité de leurs habitz ».

${ }^{36}$ Arrestz de la cour de Parlement donnez par provision les XIII d'aoust 1575 et XX de septembre 1577 pour le règlement et réformation de l'Université de Paris, Paris, Frederic Morel, 1577, p. 5.

${ }^{37}$ Ibid., p. 11.

${ }^{38}$ J. Verger, «Les universités françaises au $\mathrm{XV}^{\mathrm{e}}$ siècle : crise et tentatives de réforme », Éducation et Culture, $n^{\circ}$ spécial des Cahiers d'Histoire, 1976, p. 61-62.

${ }^{39}$ Ibid., p. 58. Le 23 juin 1588, la faculté des arts rend un décret pour exclure les gens mariés de leurs charges et du droit de suffrage au sein de leurs nations : César Égasse Du Boulay, op. cit., t. 6, p 797. En octobre 1589, Jean de Magnanes, censeur de la nation de France,
} 
maîtres qu'ils doivent renoncer au port de la barbe et à toute autre mode qui serait laïque. La fréquentation des lieux mal famés comme les tavernes est alors indigne de leur éminente dignité dont la tonsure doit être la marque apparente ${ }^{40}$. L'obligation pour les écoliers d'assister à la messe et à des lectures contrôlées de la Bible ${ }^{41}$, qui s'inscrivait autant dans une perspective d'éducation de la foi et de catéchèse que de lutte contre les protestants, est complétée par l'engagement de la faculté de théologie à rédiger un catéchisme en 1588. Celui-ci devait être enseigné dans tous les collèges de Paris ${ }^{42}$. S'il est difficile de juger de l'application effective de ces mesures disciplinaires, il est en revanche certain qu'elles correspondaient aux aspirations des laïcs, telles qu'on les rencontre dans les doléances du tiers état de Paris en 1588. Le désir de cléricalisation du personnel universitaire, que la faculté de théologie pouvait se vanter d'incarner, y était clairement exprimét ${ }^{43}$. En somme la confessionalisation, conjointement aux combats gallicans, pourrait bien avoir renforcé le magistère de la Sorbonne pendant le règne d'Henri III. Cette situation lui confère alors une légitimité à intervenir dans les débats publics sur la réforme du royaume.

\section{Au service d'un projet politique (1588-1591)}

La façon dont l'insurrection des villes, après la journée des barricades en mai 1588, conduit Henri III à donner des gages de soumission aux exigences des ligueurs est bien connue ${ }^{44}$. Désireux de montrer son attachement exclusif au catholicisme, le souverain finit par signer l'édit d'Union devant le parlement de Rouen, le 19 juillet $1588^{45}$. La faculté de théologie ne tarde pas à produire un acte d'adhésion très solennel à ce texte officiel présenté comme la solution à la crise politique que connaît le royaume. Quelle est la portée de la caution morale alors fournie par les docteurs de Sorbonne?

demande que nul ne puisse être régent s'il n'est ecclésiastique et donc célibataire. Les facultés de théologie et des arts approuvent la proposition et affrontent le refus de celles de droit et de médecine : Ibid., p. 803.

${ }^{40}$ César Égasse Du Boulay, op. cit., t. 6, p. 791.

${ }^{41}$ Arrestz de la cour de Parlement donnez par provision les XIII d'aoust 1575 et XX de septembre 1577 pour le reglement et reformation de l'Université de Paris, Paris, Frederic Morel, 1577, p. 19 : «durant les repas de disner et soupper seront leüz les livres de la sainte Bible es passaiges qui seront cottez et asignez par chacun jour par lesdits principaux et supérieurs par ordre des classes ».

${ }^{42}$ César Égasse Du Boulay, op. cit., t. 6, p. 796.

${ }^{43}$ E. Barnavi, «Les cahiers de doléances de 1588 », Annuaire bulletin de la société de l'histoire de France, 1976 (1978), p. 132-133 : Les grands maitres et régents des collèges devront être "prestres et chantans messe» et tous les dimanches un docteur en théologie viendra donner une leçon de catéchisme.

${ }^{44}$ Sur cette « réconciliation» publique entre Henri III et le duc de Guise, voir X. Le Person, 'Practiques et practiqueurs'. La vie politique à la fin du règne de Henri III (1584-1589), Genève, Droz, 2002, p. 535-547.

${ }^{45}$ N. Le Roux, Un régicide au nom de Dieu. L'assassinat d'Henri III, Paris, Gallimard, 2006, p. 133-134. 


\section{L'édit d'Union, matrice du « constitutionnalisme ligueur »}

Stéphane Rials a montré que l'édit d'Union comportait un véritable projet constitutionnel construit autour de la loi de catholicité et de la notion d'obéissance

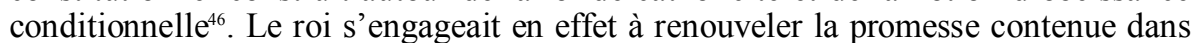
le serment du sacre : défendre l'Église et réduire l'hérésie ${ }^{47}$. En retour, et donc de façon contractuelle, les sujets juraient de conserver la fidélité due à leur souverain et de renoncer à toutes formes de ligues et d'associations partisanes ${ }^{48}$. De surcroît, le texte obligeait les sujets à refuser leur obéissance à un éventuel héritier au trône qui ne serait pas catholique ${ }^{49}$. Autrement dit, dans le prolongement de l'édit de Nemours de 1585 , qui avait mis fin à la tolérance civile et à la liberté de conscience, l'édit d'Union promouvait la loi de catholicité comme une loi fondamentale du royaume. Désormais, en matière de succession dynastique, celle-ci prenait le pas sur la loi salique. On notera ici l'écart entre l'obéissance conditionnelle des sujets et, à l'inverse, la soumission louée par les publicistes royaux convaincus que seul le souverain, de façon unilatérale, avait le droit d'abolir les lois anciennes ${ }^{50}$. Et c'est d'ailleurs sans enthousiasme que le parlement de Paris enregistra l'édit ${ }^{51}$.

En revanche, l'acte d'adhésion de l'Université suscita l'engouement et fit l'objet de cérémonies extérieures marquant avec ferveur l'union des collèges au catholicisme corporatif de la capitale ${ }^{52}$. Le recteur assembla dans l'église des Mathurins les représentants des facultés supérieures. Après lecture de l'édit, il s'agenouilla et prêta serment entre les mains du doyen de la faculté de théologie. Il

${ }^{46}$ S. Rials, "Aux origines du constitutionnalisme écrit. Réflexions en marge d'un projet constitutionnel de la Ligue en 1588 », Revue d'histoire des facultés de droit et de science juridique, 1989, p. 189-265.

${ }^{47}$ Édict du roy pour l'establissement d'un asseuré repos au faict de la religion catholicque, apostolicque et romaine et union des ses sujects catholicques avec sa Majesté, pour l'extirpation des scismes et hérésies de son royaume, pays et terres de son obéissance. Publié en sa cour de parlement de Rouen, le dixneufviesme jour de juillet 1588, Lyon, chez Jean Pillehotte, 1588, p. 7 : «Jurons et renouvellons le serment par nous faict en notre sacre de vivre et mourir en la religion catholique, apostolique [...] réduire scismes et hérésies condamnés par les saincts conciles et principalement par celui de Trente sans jamais faire aucune trefve avec les héréticques ni aucun édict en leur faveur $\gg$.

${ }^{48}$ Ibid., p. 11 : «Pareillement tous nosdicts sujects jureront de vivre et mourir en la fidélité qu'ils nous doivent et d'exposer franchement leurs biens et personnes pour la conservation de nous et de nostre auctorité et aussi des enfans qu'il plaira à Dieu nous donner envers tous et contre tous sans nul excepter $»$.

${ }^{49}$ Ibid., p. 7-8 : «Ordonnons et voulons que tous nos sujects unis jurent et promettent désaprésent et pour jamais après qu'il aura pleü à Dieu disposer de nostre vie sans nous donner des enfans, de ne recevoir à estre roy, prester obéissance à prince quelconque qui soit héréticque ou fauteur d'hérésie ».

${ }^{50}$ Par exemple Louis Le Caron dans ses Dialogues (1556) ou encore Étienne Pasquier dans son Pourparler du Prince (1560), voir A. Jouanna, Histoire et dictionnaire des guerres de Religion, Paris, Robert Laffont, 1998, p. 1054.

${ }^{51}$ S. Daubresse, op. cit., p. 434.

${ }^{52}$ César Égasse Du Boulay, Historia Universitatis Parisiensis..., t. 6, p. 797 et 798 (25 juillet 1588). 
reçut ensuite le serment des docteurs qui signèrent l'acte $d^{\prime}$ Union $^{53}$. Puis, en compagnie des docteurs des facultés supérieures, des quatre censeurs des nations et de plusieurs maîtres et professeurs, il se transporta dans tous les collèges, où principaux, régents, boursiers et écoliers prêtèrent serment à leur tour. Garante de la célébration officielle de l'édit, l'Université, portée par la faculté de théologie, fit chanter un Te Deum dans la cathédrale Notre-Dame en présence de Catherine de Médicis $^{54}$. Le rôle public grandissant de l'Université semble d'ailleurs confirmé par la monarchie elle-même qui lui accorde un droit de séance aux états généraux de Blois. Le recteur Michel Tissard ne manque pas de le souligner en rappelant qu'il s'agissait de la reconquête d'un droit qui, depuis deux siècles, n'avait plus été exercé $^{55}$. Il faut tenir compte de cette place nouvelle de l'Université dans le jeu des pouvoirs. Elle aide à mesurer la portée des résolutions prises par la faculté de théologie dans l'effervescence du soulèvement de la capitale consécutive à l'annonce du meurtre des Guises ${ }^{56}$.

\section{La légitimation de la désobéissance et de la résistance armée}

Répondant à une consultation de la municipalité parisienne, la fameuse résolution du 7 janvier 1589 se présente sous la forme d'un texte bref construit autour de deux affirmations : le peuple du royaume de France est délié et libéré de son serment de fidélité à l'égard d'Henri III $^{57}$; il lui est possible de s'armer et de collecter des fonds pour la conservation de la religion catholique ${ }^{58}$. La décision semble avoir été prise à l'unanimité par 70 docteurs de la faculté de théologie, bien que, selon Jacques-Auguste de Thou, le doyen Jacques Le Fèvre ait tenté de s'y opposer $^{59}$. Mais que pouvait bien signifier ce «serment d'obéissance» que les

\footnotetext{
${ }^{53}$ Les Archives nationales conservent une copie sur parchemin de l'édit d'Union, en date du 22 août 1588, avec les signatures des docteurs de la faculté de théologie: Arch. nat., AE II 736 (cote d'origine : M 72, pièce 22).

${ }^{54}$ César Égasse Du Boulay, Historia Universitatis Parisiensis..., t. 6, p. 800 ; M. Venard, Jehan de La Fosse Les "mémoires d'un curé de Paris (1557-1590) au temps des guerres de Religion, Genève, Droz, 2004, p. 163.

${ }^{55}$ Ibid., p. 798.

56 Dès la nouvelle du meurtre des Guises connue dans la capitale, une "assemblée révolutionnaire » prend le pouvoir à l'Hôtel de ville et nomme le duc d'Aumale gouverneur de Paris (26 décembre 1588), voir E. Barnavi, op. cit., p. 130.

${ }^{57}$ Advis et résolution de la faculté de théologie, s. 1., 1589, p. 7 : Primum quod populus hujus regni solutus est et liberatus a sacramento fidelitatis et obedientiae praefato Henrico Regi praestito.

${ }^{58}$ Ibid., p. 7 : Deinde quod idem populus licite et tuta conscientia potest armari, uniri et pecunias colligere et contribuere ad defensionem et conservationem religionis catholicae, apostolicae et romanae.

${ }_{59}$ Jacques-Auguste de Thou, Histoire universelle depuis 1543 jusqu'en 1607, t. 10, Londres, 1734, p. 512 : «Il paraissoit par l'acte qui en fut dressé que cette résolution avoit été prise tout d'une voix et sans opposition. Cependant, il étoit constant au contraire que les anciens docteurs, entr'autres le doyen nommé Jean Le Fevre, homme de bien, et qui passoit parmi eux pour habile, n'avoient point été de ce sentiment ; qu'ils avoient même détourné les jeunes docteurs d'une résolution si téméraire qui les deshonoroit à jamais et avoient été d'avis de
} 
théologiens prétendaient rayer d'un coup de plume ? L'historiographie ne semble pas en avoir fait grand cas. Pourtant, il s'agit clairement de l'obéissance des sujets telle qu'elle était contractualisée dans l'édit d'Union de 1588. Voilà pourquoi les théologiens se justifient sans étayer leur réponse par des autorités scripturaires ou canoniques $^{60}$. Estimant notamment que la «foi publique » a été violée à Blois - le meurtre des Guises qui signifie aussi implicitement la dénonciation du meurtre d'un cardinal - au préjudice de la loi de catholicité inscrite dans l'édit d'Union, ils considèrent celui-ci comme caduc. C'est ce que confirme explicitement la résolution du 8 février 1589 faisant d'Henri III celui «qui a rompu le lien de l'obligation mutuelle $»^{61}$, alors qu'il avait annoncé le caractère irrévocable de l'édit d'Union, considéré comme une loi fondamentale du royaume, aux états de Blois ${ }^{62}$. Voilà aussi pourquoi la rédaction de cette résolution ne puise à aucun moment dans l'arsenal thomiste (ou monarchomaque) de la résistance légitime au tyran ${ }^{63}$, tant la seule appréciation collective des théologiens, d'une certaine façon dépositaires de l'édit d'Union, suffisait à valider leur décision ${ }^{64}$.

Les autorités dirigeantes de la Ligue ne s'y trompent pas : après avoir purgé le Parlement, elles imposent un autre genre de serment : celui de la Sainte-Union. Les ligueurs s'y engagent à « vivre et mourir pour la religion catholique » et à juger les responsables des meurtres de Blois ${ }^{65}$. De fait, l'avis de la Sorbonne aida à vaincre l'opposition des membres du Parlement - notamment celle du premier président Achille de Harlay - qui, malgré la révolte, continuaient à exhorter la cour souveraine à se maintenir en l'obéissance du roi $^{66}$. Pour consolider les ralliements des autres villes du royaume par la prestation de ce serment, la municipalité parisienne décide alors de leur adresser, le 27 janvier 1589, une copie de la résolution du 7 janvier, en les invitant à la faire lire ou prêcher publiquement par les curés « affin que personne n'en prétende cause d'ignorance ; et ce faisant les inciter et exhorter à leur debvoir pour la manutention de leur religion et conservation de leur personne et de leurs

renvoyer au pape le jugement de cette affaire ». Sur Jacques (et non Jean) Le Fèvre, curé de Saint-Paul, voir : V. Angelo, op. cit., p. 706-707.

${ }^{60} \mathrm{La}$ question posée par la ville de Paris renvoyait clairement à l'édit d'Union, Advis et résolution de la faculté de théologie..., p. 4: «s'il est permis de s'assembler, s'unir et contribuer contre le roy et si nous sommes encores liez au serment que nous luy avons juré ».

${ }^{61}$ Advis et résolution de la sacrée faculté en théologie de Paris sur ceste question, à sçavoir s'il est loisible de jurer l'édict d'Union, Paris, chez Guillaume Chaudiere, 1589, p. 6-7.

${ }^{62}$ A. Jouanna, op. cit., p. 343 ; E. Picot, Histoire des états généraux considérés au point de vue de leur influence sur le gouvernement de la France de 1355 à 1615, t. III, Paris, 1872, rééd. Genève, 1979, p. 104-106.

${ }^{63} \mathrm{M}$. Turchetti, Tyrannie et tyrannicide de l'antiquité à nos jours, Paris, PUF, 2001, p. 267274 (sur Thomas d'Aquin) et p. 461-469 pour l'analyse des monarchomaques ligueurs.

${ }^{64}$ Toutefois la faculté de théologie s'engageait à transmettre sa résolution au pape afin qu'il l'approuve de son autorité apostolique, Advis et résolution de la faculté de théologie..., p. 8.

${ }^{65}$ Le serment de la saincte Union pour la conservation de la religion catholique et de l'Estat, Paris, par Rolin Thierry, 1589, cf. D. Pallier, Recherches sur l'imprimerie à Paris pendant la Ligue (1585-1594), Genève, 1976, n 373, p. 301.

${ }^{66}$ S. Daubresse, op. cit., p. 444-445. 
biens $\rangle^{67}$. Le 18 février, de la même façon, la capitale s'appuyait sur l'autorité de la Sorbonne - la «plus belle compagnie qui soyt en la chrestienté »-pour confirmer l'adhésion des villes à la Sainte-Union. Le rappel de la résolution du 7 janvier s'oriente alors vers un autre registre d'interprétation: l'excommunication d'Henri III. Les Parisiens estiment en effet que les théologiens « tous lesquelz d'un commun accord et consentement ont unanimement conclud et arresté que sans difficulté tous ses subjectz sont absoulz et desliez du serment de fidélité qu'ilz lui doivent estant mesme excommunié et hors de l'Église $\rangle^{68}$. Pourtant, à cette date, l'excommunication du roi était encore virtuelle. À Blois, le cardinal Morosini, légat a latere, s'était contenté au lendemain du meurtre des Guises de morigéner Henri III en l'invitant à faire pénitence et à demander l'absolution au pape ${ }^{69}$. En anticipant de trois mois le monitoire d'excommunication de Sixte Quint, ce témoignage rend compte d'une dégradation spectaculaire de l'image de la personne royale, dégradation à laquelle participa la faculté de théologie. L'historien Pierre PalmaCayet, très favorable au pouvoir royal, considérait que la publication de l'arrêt du 7 janvier avait conduit "à la révolte d'une infinité de villes» et qu'à Paris elle entraîna une multitude « d'injures et de villenies contre l'honneur du roi » ${ }^{70}$.

\section{personne}

De la négation de l'autorité du roià la désacralisation de sa

Dès la résolution du 8 février 1589 , les éléments de la titulature royale disparaissent : la faculté de théologie se contente de parler de "Henri de Valois » sans autre marque de majesté. Répondant à une question des curés du diocèse de Rouen - est-il licite de continuer à faire jurer et signer l'édit d'Union de juillet 1588 après le meurtre du cardinal de Guise ?-, l'idée même de sujétion disparaît du discours de la Sorbonne, où les demandeurs ne sont plus que « les soy disants sujects du roy $\gg^{71}$. La justification de la désobéissance renvoie alors à la résistance au tyran qui s'est rendu coupable du meurtre d'un cardinal et à ses « déportements plains de dissimulation et iniquité $\rangle^{72}$, c'est-à-dire à l'image d'un souverain sous l'emprise du diable que suggère alors efficacement la propagande ligueuse ${ }^{73}$. Les conclusions de

${ }^{67}$ F. Bonardot, Registre des délibérations du bureau de la ville de Paris, 1586-1590, t. 9, p. $273, n^{\circ}$ CCCCXLVI.

${ }^{68}$ Ibid., p. 298.

${ }^{69}$ V. Martin, op. cit., p. 248.

${ }^{70}$ A. Petitot, Pierre Palma-Cayet, Chronologie novenaire, Collection complète des mémoires relatifs à l'histoire de France, t. XXXIX, Paris, Foucault, 1824, p. 5.

${ }^{71}$ Advis et résolution de la sacrée faculté en théologie de Paris sur ceste question, à sçavoir $s$ 'il est loisible de jurer l'édict d'Union, Paris, chez Guillaume Chaudiere, 1589, p. 8.

${ }^{72}$ Ibid., p. 9 : «tous ses déportemens plains de dissimulation et iniquité ne ressentent et promettent sinon une tyrannye et une ruine totale de la religion et de l'Estat ». Reprenant les invectives des prédicateurs radicaux les théologiens présentent Henri III comme un «tyran perfide et excommunié » (ibid., p. 12).

${ }^{73}$ O. Ranum, «The French Ritual of Tyrannicide in the late Sixteenth Century », Sixteenth Century Journal, vol. 11, n 1, 1980, p. 68 ; D. Crouzet, Les guerriers de Dieu. La violence au temps des troubles de Religion, vers 1525-vers 1610, Seyssel, Champ Vallon, 1990, t. II, p. 495. 
la Sorbonne glissent ainsi de la négation de l'autorité du souverain à la désacralisation de la personne royale, processus bien visible lors de la célébration du deuil des Guises : le journal anonyme d'un bourgeois ligueur nous en fournit un témoignage très suggestif ${ }^{4}$. Maintenant la fiction de l'excommunication d'Henri III, la faculté de théologie, dans son arrêt du 5 avril 1589, décide alors de faire retirer du canon de la messe les prières pour le roi $^{75}$. Cette décision, qui touche à la piété quotidienne comme au lien communautaire, est sans doute celle qui parmi les résolutions de la Sorbonne suscite le plus l'indignation d'un notable comme Jacques-Auguste de $\mathrm{Thou}^{76}$. Surtout, elle entraîne une réorganisation du pourvoir pastoral de la capitale au profit de la faculté de théologie.

En effet, cette dernière considère que l'excommunication d'Henri III place ceux qui ont assisté ou célébré la messe en sa compagnie sous la menace de l'excommunication majeure dont ils ne peuvent être absous que par le pape ${ }^{77}$. Or c'est précisément le cas d'un prélat resté fidèle à Henri III, l'évêque de Paris Pierre de Gondi, la «bête noire de l'Université », si l'on en juge par les conflits déjà évoqués qui l'avaient opposé à cette dernière ${ }^{78}$. L'enjeu était de taille, et la faculté fit

\footnotetext{
${ }^{74}$ Henri III y est fréquemment présenté comme un «maudict tirand excommunié », voir E. Saulnier, Journal de François, bourgeois de Paris, 23 décembre 1588-30 avril 1589, Paris, Ernest Leroux, 1913, p. 23.

${ }^{75}$ Arretz et résolutions des docteurs de la faculté de Paris, sur la question sçavoir s'il falloit prier pour le roy au canon de la messe. Á laquelle sont adioustées avec licence du supérieur deux oraisons colligées pour obtenir victoire contre les ennemis, Paris, chez Denis Binet, 1589. Cette résolution est contenue dans Simon Goulart, Mémoires de la Ligue contenant les événements les plus remarquables depuis 1576 jusqu'à la paix accordée entre le roi de France et le roi d'Espagne en 1598, Amsterdam, 1758, t. III, p. 540-541.

${ }^{76}$ Jacques-Auguste de Thou, Histoire universelle depuis 1543 jusqu'en 1607, t. 10, Londres, 1734 , p. 596 : «Le 5 d'avril la Sorbonne entière, ce corps le plus célèbre qui soit dans la chrétienté, ne craignit pas de se déshonorer à jamais par le décret qui fut fait de rayer le nom $\mathrm{du}$ roi et les prières qui se font pour sa personne du canon de la messe et des collectes et de substituer à la place je ne sais quelles oraisons composées par les rebelles pour la conservation des princes catholiques $\gg$.

77 Simon Goulart, Mémoires de la Ligue, p. 540 : «Tous s'accordèrent qu'il ne falloit exprimer en aucune oraison ecclésiastique le nom de Henri à raison de l'excommunication, qu'en beaucoup de sortes et manières (comme il a été arrêté aux précédentes assemblées) il avoit encourue »; Excommunication des ecclésiastiques, principalement des évesques, abbez et docteurs, qui ont assisté au divin service, sciemment et volontairement avec Henry de Vallois, après le massacre du cardinal de Guyse..., Paris, chez Gilles Gourbin, 1589, p. 8. Ces résolutions furent suffisamment efficaces pour empêcher Jacques Amyot de regagner son siège épiscopal. Le grand aumônier du roi et évêque d'Auxerre était lui aussi visé par les censures ecclésiastiques pour avoir célébré une messe en présence d'Henri III, voir A.-C. Tizon-Germe, "Juridiction spirituelle et action pastorale des légats et nonces en France pendant la Ligue (1589-1594) », Archivium historiae pontificiae, t. 30, 1992, p. 174-175.

${ }^{78}$ En lui opposant l'attitude d'un prélat modèle comme Claude de Sainctes, Gondi était directement clairement mis en cause par l'Excommunication des ecclésiastiques..., p. 47 : «Et pour parler de notre temps, de Sainctes, évesque d'Évreux, bien qu'il ne fut pas l'évesque et pasteur du roy, comme est celuy de Paris, a bien eu le courage de blasmer et reprendre en
} 
appel à un théologien de renom, Gilbert Génébrard, docteur en théologie, hébraïsant et professeur au collège royal, pour composer un traité sur l'excommunication des ecclésiastiques, ouvrage rapidement traduit en français et donc largement diffusé ${ }^{79}$. C'est le début d'un long conflit avec l'évêque de Paris, qui ne parvient plus à exercer normalement son pouvoir pastoral et juridictionnel. À l'inverse, la faculté de théologie prétendait exercer un contrôle sur le système bénéficial et les cures parisiennes $^{80}$ avec la complicité du duc de Mayenne, lieutenant général du royaume $^{81}$. Alors qu'elle confortait la légitimité des institutions de la Ligue au sein desquelles plusieurs de ses docteurs titulaires d'une cure parisienne exerçaient un rôle dirigeant (Jean Boucher, Julien Le Pelletier, Jean Prévost) ${ }^{82}$, la faculté de théologie approuva l'insurrection ligueuse, neutralisa l'évêque de Paris et conforta donc son autorité spirituelle et temporelle. C'est ce qui explique le rôle moteur qu'elle exerça dans les mobilisations extérieures, les processions notamment ${ }^{83}$. Mais nombre d'incertitudes subsistaient sur la façon de disqualifier les prétentions dynastiques d'Henri de Navarre, héritier présomptif du trône de France. L'assassinat d'Henri III devait conduire les théologiens de la Sorbonne à fournir des réponses fortes et contradictoires à ces questions.

sa présence ses actions et le meurtre par luy commis ». Voir aussi : Acta Parisiis anno MDLXXXIX, augusto et septembri, iteratis in collegio Sorbonae comitiis super questione proposita de facto illustissimi cardinalis Gondii, episcopi Parisiensis et eorum qui cum Henrico Valesio participarunt post scelus Blesense et ei quovis modo affluerunt, Paris 1590. En mai 1591, les ligueurs conduits par Jean Boucher demandaient encore le remplacement de Gondi en qui ils voyaient un «politique », E. Barnavi, op. cit., p. 201.

${ }^{79}$ De clericis, praesertim episcopis, qui participarunt in divinis scienter et sponte cum Henrico Valesio post cardinalicidium. T. P. (Theologi Parisiensis Gilberti Genebrardi) assertio, Paris, Gilles Gourbin, 1589 ; traduction française citée supra.

${ }^{80}$ En témoigne notamment le procès de Jacques Julien, docteur en théologie, face à Claude Étienne Nouvelet, (nommé par l'évêque de Paris) pour la cure de Saint-Barthélemy. Julien demande l'intervention de l'Université pour «ordonner que nul ne put être pourvu d'aucun office ni bénéfice qui n'eut signé son engagement pour la Ligue »; le 5 avril 1592, l'Université déclare vacants les bénéfices tenus par des royalistes, voir V. Angelo, op. cit., p. 203 et César Égasse Du Boulay, op. cit., t. 6, p. 804-805.

${ }^{81}$ Articles remonstrez à monseigneur le duc de Mayenne, lieutenant général de l'Estat et couronne de France par monsieur le recteur et université de Paris le 29 novembre 1589, Paris, chez Guillaume Chaudiere, 1589, p. 8 : l'Université demande à Mayenne d'ordonner « estre faict registre de tous les bénéfices détenus par ceux du party contraire pour en faire nommer d'autres capables en leur lieu par sa saincteté ou son legat». Le lieutenant général du royaume avait déjà promis à la faculté de théologie de réserver la provision des bénéfices aux seuls ligueurs, comme le lui rappelle le recteur de l'Université : "aussi m'ont requis messieurs de la faculté de théologie vous ramentevoir la promesse qu'il vous a pleü leur faire par vos lettres escrittes d'Amiens sur la provision des bénéfices » : Ibid., p. 11.

${ }^{82}$ E. Barnavi, op. cit., p. 29-30.

${ }^{83}$ D. Richet, «Politique et Religion : les processions à Paris en 1589 », De la Réforme à la Révolution. Études sur la France moderne, Paris, Aubier,1991, p. 72. 


\section{Le choc du régicide}

Dès le 5 avril 1589, le traité de Génébrard sur l'excommunication des ecclésiastiques envisageait les conditions de la succession d'Henri III. Dans une perspective de succession héréditaire, admettant la reconnaissance de la loi salique, Génébrard estimait que le cardinal de Bourbon était le mieux placé. Henri de Navarre, neveu du précédent, était exclu selon une prétendue bâtardise et surtout en vertu de l'excommunication de Sixte Quint en $1585^{84}$. Pourtant, à l'annonce de la mort d'Henri III (2 août 1589), la faculté tarde à se prononcer aussi clairement. Alors que le duc de Mayenne ( 5 août) et le parlement de Paris (21 novembre) enjoignent aux sujets du royaume de reconnaître Charles $\mathrm{X}$ - le cardinal de Bourbon, alors détenu prisonnier par les royaux - comme leur nouveau souverain, il faut attendre l'arrêt du 10 février 1590 pour que la Sorbonne le reconnaisse officiellement $^{85}$. Cette déclaration tardive traduit sans doute l'embarras, mais aussi les divisions des théologiens devant les positions de Jean Boucher. Celui-ci approuvait le geste de Jacques Clément en popularisant des thèses favorables à une monarchie élective, niant la succession héréditaire et le caractère divin de la loi salique et proclamant que «quelque proche du sang que l'on puisse estre, l'on a aucun droit de domination en France si la pieté et vraye religion defaut $»^{86}$. De façon plus élaborée, le De justa Henrici tertii abdicatione, savant traité monarchomaque édité par Boucher en août 1589, considérait licite le régicide commis par une personne privée ${ }^{87}$. À la condition préalable que le souverain ait refusé de se

${ }^{84}$ Excommunication des ecclésiastiques, principalement des évesques, abbez et docteurs, qui ont assisté au divin service, sciemment et volontairement avec Henry de Vallois, après le massacre du cardinal de Guyse..., Paris, chez Gilles Gourbin, 1589, p. 58-59 : «L'un estant évidemment légitime, l'austre accusé de bastardise mesmes par les ministres en un livret imprimé à La Rochelle l'an 1573 pour le droict du prince de Condé à la couronne contre Henry de Bourbon roy de Navarre. L'un estant confirmé à la couronne par l'Église, nostre s. père, les estats, cours souveraines ; l'autre déposé et en oultre déclaré incapable de jamais obtenir couronne $»$.

${ }^{85}$ Il s'agissait aussi, avec le soutien du légat, de casser la dynamique des ralliements à Henri de Navarre dont les partisans suggéraient une possible conversion au catholicisme. Les prédicateurs parisiens louant la figure de Charles X comme un nouveau Melchisédech cachaient mal leurs doutes sur les chances réelles de voir un jour régner ce vieillard affaibli et prisonnier des royaux. L'arrêt du 10 février refuse le mot roi à tout autre que Charles $\mathrm{X}$ tout en interdisant d'adhérer au parti d'Henri de Navarre quand bien même ce dernier se convertirait, voir E. Saulnier, Le rôle politique du cardinal de Bourbon (Charles X), 15231590, Paris, 1912, p. 229-243.

${ }^{86}$ Lettre missive de l'évesque du Mans avec la responce à icelle faicte au mois de septembre dernier passé par un docteur en théologie de la faculté de Paris..., Lyon, chez Jean Pillehotte, 1589, p. 17. Sur l'attribution à Jean Boucher de cette "responce», voir H. Hauser, Les sources de l'histoire de France. XVI siècle (1494-1610), t. IV, Paris, Picard, 1916, p. 136 et D. Pallier, op. cit., p. 346.

${ }^{87}$ De justa Henrici tertii abdicatione e Francorum regno, Paris, chez Nicolas Nivelle, 1589. Voir M. Turchetti, op. cit., p. 462-468. Ce traité est davantage ancré dans l'actualité politique et la légitimation du tyrannicide que ne le sont les monarchomaques protestants, mais on y retrouve les mêmes thématiques sur le rejet de la tyrannie, le droit de résistance armée, le 
soumettre à la déchéance décidée par les états généraux, le Parlement, la Sorbonne ou le pape ${ }^{88}$. L'idéal d'une monarchie, où le «peuple»- c'est-à-dire, comme le précise M. Turchetti, les notables ou les sénateurs qui, aux yeux de Boucher, se distinguaient «par l'autorité de leur vertu $»^{89}$ - peut déposer ou élire le roi, reflète aussi de fortes aspirations théocratiques. Au-delà, c'est une conception de l'État monarchique chrétien, dont la finalité avant tout spirituelle serait d'œuvrer au salut des sujets, qui se dégage de l'œuvre du théologien ${ }^{90}$.

Si la faculté de théologie, à tout le moins dans la publication officielle de ses conclusions, n'adhéra pas officiellement aux thèses de Boucher en matière de succession dynastique et resta donc fidèle à la loi salique, il n'en demeure pas moins que les aspirations théocratiques de Boucher furent converties dans le désir de purifier la capitale. C'est en effet au nom d'un idéal de croisade teinté de martyrologie ${ }^{91}$ que les docteurs de Sorbonne entendent transformer Paris en boulevard du catholicisme à travers les pamphlets, les prédications et une censure active des presses parisiennes ${ }^{22}$. Davantage que l'arsenal polémique de la juste guerre puisé chez saint Augustin ${ }^{93}$, c'est au nom de «l'extrême nécessité » que le port des armes chez les religieux est justifiée ${ }^{94}$. L'on songe ici aux fameuses

contrat et l'obéissance conditionnelle, la souveraineté du peuple (états généraux) pour élire ou déposer un roi, sur ce point voir P.-A. Mellet, Les traités monarchomaques (1560-1600), Genève, Droz, 2007, p. 37-112.

${ }^{88}$ F. J. Baumgartner, Radical reactionaries : the political thought of the french catholic League, Genève, Droz, 1976, p. 134.

${ }^{89}$ M.Turchetti, op. cit., p. 463.

${ }^{90}$ M.-F. Renoux-Zagamé, Du droit de Dieu au droit de l'homme, Paris, PUF, 2003, p. 292.

${ }^{91}$ Outre le martyre de Jacques Clément dont s'emparent Boucher et la presse ligueuse, on notera la présence d'une martyrologie inspirée des persécutions subies par les catholiques anglais. Depuis l'exécution de Marie Stuart, les ligueurs accusaient en effet leurs adversaires de vouloir persécuter la religion catholique à la manière des anglicans, comme l'illustre le Discours véritable du martyre de deux prebstres et deux laycs advenu l'an mil cinq cens quatre vingt neuf à Oxfort université d'Angletterre qui pourra servir aux catholicques de la France par l'exemple d'autruy d'en avoir compassion, Paris, chez Guillaume Chaudiere, 1590. Voir les remarques de R. Descimon et J.-J. Ruiz Ibanez, Les ligueurs de l'exil. Le refuge catholique français après 1594, Seyssel, Champ Vallon, 2005, p. 24.

${ }^{92}$ Sur les permissions d'imprimer accordées par la faculté de théologie et la liste des docteurs approbateurs (parmi lesquels on retrouve Boucher, Creil, Génébrard, Feuardent, Prévost, Cueilly Dadré, etc.), voir D. Pallier, op. cit., p. 70.

${ }^{93}$ P.-A. Mellet, op. cit., p. 148-149.

${ }^{94}$ Lettre missive de l'évesque du Mans..., p. 45-46 : « en extrême nécessité (comme lors que nos forces n'estoyent encore arrivées) et en guerre deffensive, et principalement quand il y va de la religion, tout le monde est gendarme s'il faut user de ce terme. Et non seulement est permis à un chacun de prendre les armes, mais c'est chose méritoire devant Dieu [...] et quand mesmes les plus austères, comme Chartreux ou Cappucins sortiroyent de leurs cloistres et celules pour ceste effect, il n'y auroit coulpe mortelle ny vénielle ains occasion de mériter, la charité les mouvans à exposer leur vie pour le repos public, pour le bien de l'Église et la cause de Dieu [...] Et pleüt a Dieu qu'il ne tinst qu'à pendre habit de Cordelier ou Jacobin et aller mesme en forme de procession comme firent jadis les enfans d'Israël autour de Hierico 
processions en armes menées par l'évêque de Senlis, Guillaume Rose, en mai 1590, en compagnie de moines portant hallebardes et arquebuses ${ }^{95}$. Au même moment la faculté de théologie assurait que ceux qui s'opposeraient jusqu'à la mort à l'accession d'Henri de Navarre au trône, "comme deffenseurs de la foy, remporter[aient] la palme du martyre $»^{96}$. Si le siège de Paris constitue bien le paroxysme de ce type de mobilisation catholique, il faut noter que, dès l'automne 1589, le recteur de l'Université, Jean Yon, faisait connaître au duc de Mayenne les dispositions militantes des collégiens mécontents du manque de zèle des autorités civiles : «nos escoliers et petits enfants qui crient continuellement vengeance du sang encore chaud et fraîchement espandu de leurs parents et amis $»^{97}$. Un peu plus tard, son successeur Jean de Magnanes (élu recteur en décembre 1589, puis prolongé en mars 1590) compare la défense armée de la capitale par les étudiants à l'attitude des Hébreux qui, sous Néhémias, bâtissaient le temple d'une main et de l'autre repoussaient les ennemis ${ }^{98}$.

Au-delà de la mobilisation des populations étudiantes dans les rangs de la Ligue, qui reste à étudier, l'Université se rapproche par ses déclarations officielles de la frange radicale de la bourgeoisie parisienne, qui hantait le conseil général de l'Union et dont les chefs- les Seize - reprochaient au duc de Mayenne sa modération à l'égard des protestants et des partisans d'Henri de Navarre ${ }^{99}$. Ainsi le recteur de l'Université remit un ensemble de propositions législatives et institutionnelles, le 29 novembre 1589, destinées à épurer la capitale des opposants à la Sainte-Union. Outre le procès et la saisie des biens de «ceux qui sont du party contraire $»^{100}$, l'Université proposait un renforcement de la police dans tous les registres - de la lutte anti-blasphématoire au contrôle de l'approvisionnement en blé - s'appuyant davantage sur les quartiers parisiens et leurs instances représentatives ${ }^{101}$. Dans le contexte de militarisation de la société, une plus grande

que nous n'eussions la fin du Biarnois et de ses adhérans on en dispenseroit bien sans aller à Rome» .

${ }^{95}$ G. Chaix, «Idéal érémitique et réalités ligueuses dans la France d'Henri III », Henri III en son temps. Actes du colloque international du centre de la Renaissance de Tours, Robert Sauzet, Tours, 1992, p 200 et A. W. Ramsey, Liturgy, Politics and salvation. The catholic League in Paris and the nature of the catholic reform, 1540-1650, Rochester-New York, University of Rochester Press, 1999 p 76-80.

${ }^{96}$ Résolution de messieurs de la faculté de théologie de Paris. Sur les articles à eux proposez par les catholiques habitans de la ville de Paris, touchant la paix ou capitulation avec l'hérétique et admission de Henry de Bourbon à la couronne de France. Avec une lettre aux habitans catholiques des villes de la France qui ont juré la saincte union, Paris, chez Sébastien Nivelle, 1590, rééd. Lyon, chez Jean Pillehotte, 1593, p. 16.

${ }^{97}$ Articles remonstrez à monseigneur le duc de Mayenne, lieutenant général de l'Estat et couronne de France par monsieur le recteur et université de Paris le 29 novembre 1589, Paris, chez Guillaume Chaudiere, 1589, p. 13.

${ }^{98}$ César Égasse Du Boulay, op. cit., t. 6, p. 805.

${ }^{99}$ E. Barnavi, op. cit., p. 199-203.

${ }^{100}$ Articles remonstrez à monseigneur le duc de Mayenne..., art. III, p. 5.

101 Ainsi, en nommant quatre «notables bourgeois» aux côtés du lieutenant civil pour s'occuper de la police du blé, ibid., p. 5. 
discipline des soldats était espérée par l'institutionnalisation de prédicateurs et de confesseurs les entretenant régulièrement en la crainte de Dieu ${ }^{102}$. Le renforcement de la lutte contre l'hérésie devait emprunter la restauration d'un tribunal d'exception, dont le modèle évoqué est la chambre ardente créée par François I ${ }^{\mathrm{er}_{103}}$. Tout au long de la Ligue, cette demande, qui figurait déjà dans les doléances du tiers état de Paris en 1588, fut réitérée par le projet politique radical des Seize. Malgré de multiples demandes, ces derniers ne parvinrent pas à convaincre Mayenne et les membres de son conseil d'État ${ }^{104}$.

Les doléances portées par le recteur de l'Université témoignent donc bien d'une collusion avec le programme politique des Seize : tandis que la milice urbaine devait être purgée « des colonels et capitaines suspects $»^{105}$, le conseil d'État du duc de Mayenne devait subir une transformation voisine pour ne comporter que des ligueurs zélés ${ }^{106}$. Et les mêmes doléances furent reconduites à plusieurs reprises de septembre 1590 à septembre 1591, Jean Boucher n'hésitant pas à se faire l'interprète auprès de Mayenne, fort du soutien du pape Grégoire XIV et de Philippe II d'Espagne, de la détermination des Seize à conduire une guerre sans merci contre Henri de Navarre, les protestants et les politiques ${ }^{107}$. Le soutien aux Seize ne devait pas faiblir. Ainsi, lorsque ces derniers, en août 1591, s'opposèrent à l'élection d'échevins suspectés d'être des "politiques ", un mémoire de l'Université fut opportunément composé pour en contester la validitéer ${ }^{108}$. Dès lors, il est tentant d'expliquer le déclin de l'autorité de la Sorbonne par la compromission de celle-ci dans l'activisme des Seize les plus intransigeants. Consultée dans le secret, la faculté de théologie aurait en effet donné son approbation au coup de force qui devait conduire, le 15 novembre 1591, au procès expéditif puis à l'exécution du président Brisson et des magistrats Jean Tardif et Claude Larcher ${ }^{109}$. L'échec des ligueurs radicaux dans cette affaire et les représailles sévères que leur infligea par la suite le duc de Mayenne seraient alors à l'origine de la mise sous l'éteignoir de l'autorité de la Sorbonne après 1591. C'est oublier que les théologiens compromis furent épargnés par la répression. Surtout, à trop lier cette explication à la contingence politique, on risque de perdre de vue que l'unanimisme (de façade ?) de la faculté de théologie au début de la Ligue ne fut guère durable.

\footnotetext{
${ }^{102}$ Ibid., p. 11, art. XVIII.

${ }^{103}$ Ibid., p. 12, art. XXI.

${ }^{104}$ E. Barnavi, op. cit., p. 210.

${ }^{105}$ Articles remonstrez à monseigneur le duc de Mayenne..., art. VIII, p. 7.

${ }^{106}$ Ibid., art. IX, p. 7-8 : «Ne vous servir en conseil que de gens de conscience et bonne réputation qui dressent selon Dieu vos affaires au but de la religion et repos public pour lequel vous combattez ».

${ }^{107}$ E. Barnavi, op. cit., p. 199-201.

${ }^{108}$ Ibid., p. 197-198 et César Égasse Du Boulay, op. cit., t. 6, p. 805 : le syndic de l'Université refusa d'accorder valeur au mémoire, mais l'Université dépêcha tout de même Jean Boucher au conseil pour aider à invalider l'élection de l'Hôtel de ville (28 août 1591).

${ }^{109}$ E. Barnavi et R. Descimon, La sainte Ligue, le juge et la potence. L'assassinat du président Brisson (15 novembre 1591), Paris, Hachette, 1985.
} 


\section{Une institution divisée, une influence déclinante (1591-1594)}

Alors que l'Université s'était prononcée à plusieurs reprises sur les questions dynastiques en 1589 et 1590 , elle occupe un rôle tout à fait marginal lors des débats des états généraux de 1593 pourtant réunis afin d'élire un nouveau souverain ${ }^{110}$. Immobilisme politique et persistance de divisions internes furent-ils les seules contributions à son effacement ?

\section{Une perte d'autonomie consécutive aux ingérences extérieures}

L'arbitrage de la papauté dans les affaires politiques du royaume de France s'opéra par l'envoi successif du légat Enrico Caetani (à Paris en janvier 1590), du nonce Marsilio Landriano (janvier 1591) et du légat Filippo Sega (de 1592 à 1594). Tous trois étaient pourvus de pouvoirs juridictionnels, diplomatiques et pastoraux (bulles de faculté) qui vinrent concurrencer et même prendre le pas sur l'autorité de la faculté de théologie. On assista ainsi à une intervention croissante des hommes du pape dans les questions bénéficiales, dans le contrôle de la prédication et même dans la censure des livres ${ }^{111}$. Cette nouvelle donne est perceptible dans la résolution de la faculté de théologie du 10 février 1590 qui, de façon significative, est accompagnée des lettres de Sixte Quint recommandant et instituant le légat Caetani ${ }^{12}$. Par ailleurs, Francesco Panigarole, célèbre prédicateur franciscain de la légation de Caetani, participa directement à la rédaction de la résolution du 7 mai 1590 avec la ferme intention de neutraliser les ambitions d'Henri de Navarre ${ }^{113}$. Cependant, d'autres théologiens, dès avant la mort du cardinal de Bourbon en mai 1590, avaient dû envisager publiquement de reconnaître Henri IV si celui-ci prenait le chemin de la messe. Entre les ligueurs radicaux, qu'ils soient ou non espagnolisés, et ceux qu'on devait appeler plus tard les «semonneux », des divisions certaines traversèrent la

\footnotetext{
${ }^{110}$ A. Bernard, Procès-verbaux des états généraux de 1593, Paris, Imprimerie nationale, 1842. Aucun théologien de Sorbonne ne publia le moindre argument contre la loi salique alors qu'un juriste espagnol, Rodrigo Capata, avait mobilisé des "preuves » historiques pour contredire cette loi de succession au trône : appliquée seulement à partir du $\mathrm{XIV}^{\mathrm{e}}$ siècle, la primogéniture masculine ne pouvait selon lui que concerner les Valois et non les Bourbons (et donc Henri de Navarre) séparés de la lignée royale deux générations plus tôt, voir R. Giesey, Le rôle méconnu de la loi salique : la succession royale, XIV ${ }^{e}-X V I^{e}$ siècles, Paris, Les Belles Lettres, 2007, p. 250.

${ }^{111}$ A.-C. Tizon-Germe, «Juridiction spirituelle et action pastorale des légats et nonces en France pendant la Ligue (1589-1594)», Archivium historiae pontificiae, t. 30, 1992, p. 161230 ; Ead., «La représentation pontificale en France au début du règne d'Henri IV (15891594), cadre politique, moyens humains et financiers, Bibliothèque de l'École des chartes, année 1993, vol. 151, $\mathrm{n}^{\circ} 1$, p. 37-85.

${ }^{112}$ Acte de ce qui s'est passé au collège de Sorbonne en l'assemblée de la Faculté de théologie, le dixiesme de febvrier \& jours consécutifs, pour confirmer l'union. Avec la traduction de deux missives envoyées de Rome à la mesme Faculté, Paris, chez Guillaume Chaudiere, 1590, p. 10.

113 A.-C. Tizon-Germe, «La représentation pontificale en France au début du règne d'Henri IV (1589-1594), cadre politique, moyens humains et financiers, Bibliothèque de l'École des chartes, année 1993, vol. 151, n 1, p. 59.
} 
faculté de théologie pour que celle-ci soit obligée de légiférer le 10 février 1590. Elle exhortait alors tous ses « docteurs, bacheliers et autres enrollez en icelle » à faire savoir qu'il n'y a aucun "schismes et dissensions entre eux ${ }^{114}$. En exigeant de ses membres un serment niant toute légitimité au trône à Henri de Navarre, la cause des divisions était clairement précisée ${ }^{115}$.

L'étude des milieux et des réseaux qui innervaient l'Université, ainsi que celle de leur évolution ultérieure restent à entreprendre. Elle fut sans doute tiraillée, comme l'ensemble de la société parisienne, par les divisions qui donnèrent naissance à autant de courants au sein de la Ligue parisienne à partir de 1591 (espagnolisés, guisards, mayennistes, catholiques royaux, politiques, etc. ${ }^{116}$. Dès septembre 1591 , les Seize avaient écrit une missive à Philippe II pour littéralement lui offrir le trône de France ${ }^{117}$. Parmi les signataires figuraient les docteurs en théologie Gilbert Génébrard et B. Martin tandis que l'hispanophilie de Jean Boucher n'était un secret pour personne. Mais en 1593 l'influence des théologiens liés à l'Espagne devait compter avec le jeu des brigues et des menées des clientèles nobilaires né des candidatures multiples au trône ${ }^{118}$ : celles de l'infante Isabelle Claire Eugénie, du duc de Savoie Charles-Emmanuel, du duc Charles de Lorraine, du fils du duc de Mayenne, du jeune duc de Guise ou encore du marquis de Pont-à-Mousson, etc. Un indice en rend compte : le 7 mai, les membres de l'Université ne parvinrent pas à se mettre d'accord sur une question de préséance : entre le duc de Mayenne et le duc de Guise, qui tous deux étaient rivaux, lequel fallait-il aller saluer en premier ${ }^{119}$ ?

\section{Le zèle menacé? Gallicanisme et espoirs de paix}

Les « semonneux », ces catholiques modérés et amateurs de paix, espéraient « semondre » Henri IV pour qu'il se convertisse au catholicisme. Leur action dans la capitale est attestée dès l'automne 1592 autour de l'abbé de Sainte-Geneviève, Joseph Foulon, et du curé de Saint-Eustache, René Benoist ${ }^{120}$. Certains d'entre eux

114 Acte de ce qui s'est passé au collège de Sorbonne en l'assemblée de la Faculté de théologie, le dixiesme de febvrier \& jours consécutifs, pour confirmer l'union. Avec la traduction de deux missives envoyées de Rome à la mesme Faculté, Paris, chez Guillaume Chaudiere, 1590, p. 4.

${ }^{115}$ Ibid., p. 9 : Forme du serment faict par ceux qui ont esté présents, et à faire cy après : «Je $\mathrm{N}$. promets et jure sainctement que j'approuve tous les articles susdicts, et déterminations de ma mère la Faculté de Paris et que je ne prescheray ou dirai jamais rien qui y contrevienne ny qui puisse servir à promouvoir, advancer ou fortifier le party du Navarrois hérétiques, relaps et excommunié, ou de ceux qui le favorisent et supporteront désormais, ny ne puisse nuyre en quelque sorte et manière que ce soit à la Saincte Union des Catholiques ».

${ }^{116}$ R. Descimon, «La Ligue à Paris : une révision », Annales ESC, 1982, vol. 37, p. 93.

${ }^{117}$ P. Paris, Correspondance du roi Charles IX et du sieur de Mandelot gouverneur de Lyon pendant l'année 1572. Lettre des Seize au roi d'Espagne Philippe II, année 1591, Paris, 1830, p. 126.

${ }^{118}$ L. Davillé, Les prétentions de Charles III, duc de Lorraine, à la couronne de France, Paris, 1908, p. 259.

${ }^{119}$ César Égasse Du Boulay, op. cit., t. 6, p. 813.

${ }^{120}$ P. Pasquier, Un curé de Paris pendant les guerres de Religion. René Benoist, le pape des Halles (1521-1608), Angers, C. Grassin, rééd. Genève, Slatkine, 1970, p. 218-219. 
avaient aussi été effrayés par les prétentions de l'Université, dans son conflit avec Gondi, à empiéter sur le magistère épiscopal. C'est ce qu'exprimait René Benoist lorsque, au nom de l'Église gallicane, il s'était adressé au pape Pie V pour lui demander d'agir en faveur du rétablissement de la hiérarchie ecclésiastique ${ }^{121}$. Par la suite, sans tenir compte de ces récriminations gallicanes, la faculté de théologie se contenta de recycler le programme politique des Seize en se polarisant sur la lutte contre l'hérésie, la défense de la loi de catholicité et la réception du concile de Trente. Comme l'a noté E. Barnavi, les propositions de l'Université du 25 janvier 1593 ne comportaient aucune référence aux libertés gallicanes que l'Université avait pourtant si ardemment défendues pendant le règne d'Henri III ${ }^{122}$. Enfin, l'intransigeance de la faculté de théologie, qui le 19 février 1593 appuya le rejet des Seize des conférences de Suresnes et de toute idée de trêve ${ }^{123}$, fut impuissante à enrayer la dynamique de paix qui devait s'imposer et contribuer à démobiliser les ligueurs. Le rejet des prétentions espagnoles aboutit à la Suasion de l'arrest pour la manutention de la loi salique, fameuse harangue de Guillaume Du Vair, et au non moins fameux arrêt Lemaistre du parlement de Paris (28 juin 1593) proclamant l'inviolabilité de la loi salique en matière de succession dynastique ${ }^{124}$. C'est le parlement qui s'imposa alors comme le gardien des lois fondamentales du royaume, reléguant à l'arrière plan les états généraux et encore plus la faculté de théologie. Malgré la conversion du roi, aucun acte officiel de l'Université ne semble d'ailleurs avoir été imprimé entre le 7 mai 1590 et le 22 avril 1594, date de sa soumission à Henri IV ${ }^{125}$.

Il faut considérer qu'en 1593 la ligne du refus adoptée par les théologiens radicaux monarchomaques, dans leurs pamphlets comme dans leurs sermons, était à contre-courant de deux vagues de fond qui traversaient la population parisienne et les députés des états généraux : l'aspiration à la paix - le tiers état et la noblesse

\footnotetext{
${ }^{121}$ Requeste presentée à nostre très sainct très constant et très vigilant Père le pape Sixte $V$ pour et au nom de l'Église gallicane misérablement tourmentée et assiégée, Paris, Pierre Le Roy, 1589, non paginé : "Faites donc en sorte (ô Père très sainct) que par vostre zèle, par vostre providence et sagesse, la hiérarchie ecclésiastique reluise et donne derechef sa splendeur en ses ministres légitimes et divinement instituez: assavoir, les évesques, les prestres et les diacres approuvez canoniquement tant en la vie, science que es mœurs » (lettre datée du $1^{\text {er }}$ novembre 1589 ).

${ }^{122}$ E. Barnavi, op. cit., p. 227.

${ }^{123}$ Ibid., p. 226-229.

${ }^{124}$ R. Radouant, Guillaume du Vair. L'homme et l'orateur jusqu'à la fin des troubles de la Ligue (1555-1596), Paris, 1907, p. 312.

${ }^{125}$ Acte public touchant l'obéissance rendue, jurée et soubsignée au très chrestien et très clément Henri IIII roy de France et de Navarre nostre vraye et unique prince et seigneur naturel, faict par monsieur le recteur de l'université de Paris et messieurs les doyen et docteurs de la très sacrée facultée de théologie..., Paris, chez Denis Du Pré, 1594. Les ligueurs proscrits ou en exil organisèrent une réplique à cet acte. Jean Boucher qui avait quitté la capitale en compagnie du duc de Féria, pour trouver refuge à Amiens où s'organisait «un Paris ligueur en miniature ", édita ainsi une résolution avec onze théologiens de Sorbonne (29 avril). Celle-ci appelait à la poursuite de la guerre contre le roi de Navarre, voir R. Descimon et J.-J. Ruiz Ibanez, op. cit., p. 98-99.
} 
étaient favorables à une trêve - et le sentiment national que les partisans d'Henri IV agitaient habilement face aux prétentions espagnoles ${ }^{126}$. Le refus majeur d'Henri IV et en corollaire l'adoption par une partie des docteurs de Sorbonne des thèses qui avaient légitimé le régicide d'Henri III' ${ }^{127}$, en divisant l'Université l'empêchaient désormais d'incarner cette conscience gallicane de la France qui lui avait précisément valu de jouer un rôle politique de premier plan à la fin du règne d'Henri III. Les publicistes royaux ne se privèrent pas de mettre en lumière cette contradiction qui contribua à l'érosion de son magistère ${ }^{128}$.

Thierry Amalou

Université Paris 1 Panthéon-Sorbonne

CRHM (EA 127)

${ }^{126}$ M. Yardeni, La conscience nationale en France pendant les guerres de Religion (15591598), Louvain-Pairs, Nauwelaerts, 1971, p. 263-281.

${ }^{127}$ Dès le mois d'août 1593, Jean Boucher fustigea ce qui à ses yeux n'était que la «simulée conversion » d'Henri IV à Saint-Denis : Sermons de la simulée conversion et nullité de la prétendue absolution de Henry de Bourbon, Prince de Béarn, à S. Denys en France, le dimenche 25 juillet 1593, Paris, chez Guillaume Chaudiere, 1594.

${ }^{128}$ Les presses royalistes, à grand renfort d'érudition historique, rappelaient que déjà au temps de la guerre de Cent Ans (qui, comme la Ligue, était une guerre civile livrant la France aux appétits des puissances étrangères), un théologien de Sorbonne, le célèbre Jean Petit, s'était employé «par passages dépravez de l'Escriture saincte [...] que le meurtre (du duc d'Orléans) avoit esté justement et licitement commis », Discours sur la Résolution de la faculté de théologie de Paris faicte le septiesme janvier mil cinq cens quatre vingts et neuf, Paris, 1589, p. 100. Les thèses extrêmes des théologiens ligueurs étaient ainsi discréditées par une filiation antinationale qui tranchait avec les vertus et le gallicanisme contemporains d'un Gerson. 